Erikson, D. \& Porteous, J. W. (1955). J. gen. Microbiol. 13, 261-272

\title{
Commensalism in Pathogenic Anaerobic Actinomyces Gultures
}

\author{
By DAGNY ERIKSON and J. W. PORTEOUS \\ Department of Bacteriology and the Department of Biological Chemistry, \\ University of Aberdeen
}

\begin{abstract}
SUMMARY : Conversion of a 'rough' typical strain of Actinomyces israelii of human origin to a 'smooth' soft form more tolerant of oxygen was found to result from the physical trapping within the mycelium of a few alien and facultatively anaerobic cells. Such cells, which commonly proved to be staphylococci, were isolated in single cell culture by micromanipulative techniques and then grown aerobically. Their presence affected the morphology and oxygen tension requirements of the host. In successfully balanced mixtures the colonies appeared homogeneous anaerobically and failed to grow aerobically. The commensal organism could most readily be detected in a water/gel system in stoppered bottle cultures. Similar associations were obtained from a variety of morbid material, especially that of bovine origin. It is suggested that the descriptions given by various workers at different times of a smooth soft micro-aerophilic organism little given to branching may cover: (1) $\mathrm{A}$. israelii and associates; or (2) a distinct organism earlier described under the name of A. bovis.
\end{abstract}

Throughout the extensive literature on the anaerobic pathogenic actinomycetes, there are certain recurrent themes which have elicited much discussion. They are:

(1) In the animal host, even in closed lesions, all actinomycetes are accompanied by other micro-organisms (Klinger, 1912; Colebrook, 1920; Bates, 1933; Holm, 1950).

(2) Although on primary isolation strictly anaerobic, organisms may on subsequent cultivation tolerate some degree of oxygen tension (Bisset \& Moore, 1949; Ludwig \& Sullivan, 1952; Prévot, 1953).

(3) While the classic Actinomyces israelii produces a 'rough' irregularly shaped colony on the surface of complex media such as blood agar, together with a breadcrumb type of growth in liquid media, there may arise 'smooth' dissociants which are composed of shorter diphtheroid or bacillary cells less prone to branching and thus more evenly dispersed in liquid media (Lentze, 1938; Morris, 1951; Ludwig \& Sullivan, 1952).

(4) Soft diphtheroid strains producing such 'smooth' colonies can also be obtained in primary isolation from morbid material of human origin (groups II and III of Holm, 1948; Slack, Ludwig, Bird \& Canby 1951), and of animal origin (Magnusson, 1928; Kimball \& Frank, 1945; Thompson, 1950). These strains are less strictly anaerobic than the 'rough' ones, and sometimes require carbon dioxide.

One particular aspect of these themes is presented here. 


\section{METHODS}

The media employed throughout were the stock medium (S) or the dilution media (A to F) of Erikson \& Porteous (1953). Anaerobiosis was obtained by flushing the container vessels with nitrogen in the manner described in that paper. Water/gel cultures were prepared in small screw-capped bottles according to the method of Heald, Krogh, Mann, Appleby, Masson \& Oxford (1953), with the modification that the concentration of agar in the solid layer was only $0.5 \%$. When this nutrient layer incorporating the inoculum had set, the bottle was carefully filled with freshly-boiled cold sterile water up to the rim and the cap screwed down.

Micromanipulations were carried out according to the methods of Erikson \& Masson (1954). Daily examinations of growing cells were made by means of phase-contrast and bright-field microscopy.

Seven human strains of typical Actinomyces israelii were used; all had been recently isolated from cases of actinomycosis, and five of them had already been shown to have similar powers of utilizing glucose with the production of lactic acid (Erikson \& Porteous, 1953). In addition, about 120 specimens of morbid material from animal sources, reputedly actinomycotic in origin, were obtained from the local slaughter-house and from veterinarians in different parts of the country. The specimens were examined histologically, and attempts to obtain cultures were made in almost all cases, using a variety of customary procedures. The great majority of the specimens were bovine in origin, but a few were from sow udders.

\section{RESULTS}

It will be more convenient to consider first the practical details involved in the above aspects (2) and (3) of the problem: conversion of hard 'rough' to soft 'smooth' growth with increased tolerance of oxygen and turbidity of shortcelled liquid cultures.

\section{Spontaneous origin of 'smooth' groreth}

After about 18 months of continuous weekly subculture of seven human strains of Actinomyces israelii in S (glucose heart-broth casein digest) liquid medium, during which period the yields and appearances of the organisms were much the same for all strains, it was noticed that one particular strain (1394) was growing more profusely than the others. When the routine microscopical examinations made before subcultivation were checked, it was found that the micro-colonies of strain 1394 were on the whole characteristic if rather shrunken (Pl. 1, fig. 1), but that their component cells were shorter and less regularly branched (Pl. 1, fig. 2). When plated out, the organism seemed homogeneous, even though the cultures were rather smoother than usual. Liquid cultures still retained their clarity, but after four more subcultures a certain 'incohesiveness' had become quite perceptible, i.e. normally discrete compact 
colonies when gently shaken in the tube fragmented readily, thus bringing about a slight turbidity of the medium.

At this stage strain 1394 was inoculated into tubes of the various dilution media $\mathbf{A}$ to $\mathbf{F}$ (six replicates of each); their subsequent history was as follows:

1st week: $\mathrm{S}$ tubes all turbid; $\mathbf{A}$ to $\mathrm{C}$ similar; $\mathrm{D}$ to $\mathbf{F}$ typical growth and clear media:

2nd week: from $\mathrm{D}$ medium to $\mathrm{D}$ medium-short to moderately long filaments, sometimes branched, and short rods (Pl. 1, figs. 3-5); from F medium to $\mathbf{F}$ medium-rods and short filaments cohering with small cocci (Pl. 1, fig. 6-9).

3rd week: to $\mathbf{D}$ medium from $\mathbf{F}$ medium-filaments at margin of microcolony, centre less defined ( $\mathrm{Pl}$. 1, fig. 10); to $\mathrm{F}$ medium from $\mathrm{F}$ mediumsimilar; plate of D medium from D liquid--smooth glistening colonies showing short rod and diphtheroid components (PI. 1, fig. 12).

4th week: to D medium from D medium-much fragmentation, some longer filaments; to S medium from D medium--similar, fewer filaments.

During this period of 4 weeks the original profuse growth had also been subcultured aerobically in $\mathrm{S}$ medium with remarkable degree of continuity for 6 subcultures, but now in the 8th subculture it showed a decided falling off. Single smooth colonies from an anaerobic plate of medium $D$ were then suspended so that the cells of any one colony were used as inoculum for both aerobic and anaerobic cultivation, with these results:

Aerobic: S medium mostly turbid-short rods and cocco-bacilli; $\mathbf{A}$ to $\mathbf{D}$ media-gradually more rods and short filaments; $\mathrm{E}$ and $\mathrm{F}$ media the clearest fluid and most typical branched filaments;

Anaerobic: S medium mostly clear-rods and cocci cohering with short filaments (Pl. 1, figs. 6, 7); $\mathrm{A}$ to $\mathrm{D}$ media mostly rods and filaments; $\mathrm{E}$ and $\mathrm{F}$ media more branching of filaments, all clear.

When these various cultures were subcultured four more times the aerobic cultures died out while the anaerobic ones presented much the same picture as that noted in the 4th week above. By repeated subculture of these growths in the more dilute media $\mathrm{D}$ to $\mathrm{F}$, we succeeded by about the 12 th week in stabilizing a form which appeared pure. Colonies in liquids were discrete and cohesive, even in the richest $\mathrm{S}$ medium, and, although the growth was a little soft to the touch, no clouding of the medium occurred at any stage. Colonies on slopes were raised and nodular, though smooth and glistening instead of rough and pebbled.

A return was also made to the slope and shake cultures which had been prepared as a routine before beginning these series of tests. The shake cultures appeared characteristic, but were no longer viable. The slope cultures exhibited a considerable amount of soft spreading growth, with isolated typical but rather smooth colonies at the margin. Morphologically they were similar to the cell complexes described above as appearing during the first week in S liquid media. It was therefore considered possible that: $(a)$ the organism had been superseded by a contaminant; $(b)$ the organism had undergone a spontaneous 
dissociation, and the two types had co-existed for a time until the smooth dissociant had supplanted the original form; or, $(c)$ the organism was living commensally with a contaminant whose numbers varied according to cultural conditions and so affected the gross and particular appearances of the host.

The fact that normal aspect and morphology tended to be associated with the less rich dilution media $\mathbf{D}$ to $\mathbf{F}$ favoured hypothesis $(c)$. Yet the contaminant, if any, did not seem to be separable by means of ordinary dilution and plating procedures with the media and anaerobic conditions used. Moreover, the aerobic liquid cultures mentioned earlier had died out, and it was therefore doubtful whether an aerobic or micro-aerophilic organism had been present from the first appearance of the phenomenon. In the circumstances it was decided to attempt single-cell isolations.

\section{Single-cell isolations by micromanipulation}

Four stocks of organisms of strain 1394 were used to provide the initial pools for micromanipulation (Erikson \& Masson, 1954). The immediate history of these four stocks was as follows:

Stock (1): 5-day anaerobic growth in liquid medium A from single colony on a slope of $\mathbf{F}$ medium.

Stock (2): 5-day anaerobic growth in liquid medium A from single colony on a $\mathbf{D}$ medium plate.

Stock (3): 5-day anaerobic growth in liquid medium A from culture in liquid medium $\mathbf{D}$ derived from a smooth colony on medium $\mathrm{D}$ plate.

Stock (4): 5-day anaerobic growth in liquid medium A from liquid medium $\mathbf{S}$ derived from a culture in liquid medium $\mathbf{F}$.

Stocks (1) and (2) were the more typical in appearance, while stocks (3) and (4) were softer and the component cells less coherent, but the medium was clear before shaking.

All four stocks were used in the original series of micromanipulative experiments which, as far as isolation of a typical actinomycete was concerned, represented the many failures mentioned in the earlier work of Erikson \& Masson (1954). At that time efforts were confined to attempts to grow the cells within the droplets in the oil chamber, with flushing of the system repeatedly with nitrogen to decrease the amount of dissolved oxygen in the oil and medium, and subsequent incubation of the chamber in an anaerobic jar. The only cells which did develop under these conditions were certain short cell elements in stocks (1), (2) and (4). These short cell elements multiplied in the droplets as cocci, and when transferred to slopes of nutrient agar and incubated aerobically grew vigorously as a pure culture of Gram-positive cocci on repeated subculture. They were subsequently identified as Staphylococcus albus by comparison with an authentic culture. The droplets of medium that were uninoculated all proved sterile. Nor was any growth obtained in the series of droplets sown with stock (3), the single cells that had been separated in this instance being preponderantly rod- or filament-shaped. 
As will be seen from Pl. 1, figs. 6-9, it was often difficult to decide whether or not the coccoid cells evident in such growths in stock cultures were in fact attached to the longer cells. When the charts giving the positions and shapes of every cell in the droplets were examined, it was apparent that an undue proportion of the short cell elements had been transferred to the slide. This was explained by the selective action of capillarity within the very slender tip of the finely drawn pipette with which the stock culture was sampled for the initial pool of cells. The preponderance in certain slides of these round cells was therefore not at first regarded with too much misgiving, but when it was found that only these cells grew in a system which de Fonbrune (1949) had described as unsuitable for the development of strict anaerobes, the evidence seemed conclusive that they were indeed alien cells.

Cultivation of single filaments or diphtheroid rods, with ensuing characteristic mycelial growth, was not achieved until the period within the oil chamber had been decreased to the minimum and the cells were incubated on solid media in an anaerobic slide-carrier drum (Pl. 1 of Erikson \& Masson, 1954), or in semi-solid media in a water + gel system in stoppered bottles (Fig. 2 of Erikson \& Masson, 1954). The mode of growth was similar in all instances, whether the initial cells were taken from the shorter diphtheroid forms or from slender filaments with the occasional club-shaped swellings that may be encountered particularly in liquid glucose-containing media (Pl. 2, fig. 15); or from the relatively longer and more homogeneous filaments developing between coverslip and agar in a slide culture (Pl. 2, figs. 16, 17). As recorded earlier (Erikson, 1940, pp. 16-18, 54-7, figs. 1-14), the growing cell elongates and in doing so may remain straight producing a branch, which itself elongates and branches in other directions (Pl. 2, figs. 20, 21); or it may bend at an angle, and immediately after branching a septum may be formed, allowing the new branch to slip sideways in characteristic angular apposition (Pl. 2, fig. 20).

The variety of planes through which these delicate filaments pass even in the restricted space between coverslip and agar is obvious from the fact that some portion of the minute growth is constantly out of focus (cf. Colebrook, 1920 , who stated that the organism seldom ran straight for more than $20 \mu$.). Yet by focusing up and down the continuity of the cells could always be determined. Thus, in Pl. 2, fig. 18, the growing tip of the uppermost branch appears more bud-like and clavate than it really was, simply because the branch was beginning to turn over and the tip to burrow into the agar; and in Pl. 2, fig. 20, the apparent inequalities in diameter of the $V$-shaped growth at the bottom of the picture are due to the many slight twists in orientation, as well as to the development from one limb of a lateral branch which is almost entirely out of focus. Yet the slenderness of the uppermost portion of this filament, which after being cut off from the initial right-angled parent cell had slipped sideways, was real-not an artefact-and very characteristic of one mode of growth on solid media. In Pl. 2, fig. 21, the very beginning of a small branch can be seen in the centre right as a minute almost globular bud with very slender stalk. The close overlaying of different branches, which in fixed stained 
preparations can sometimes give the impression of enlarged or fused cells, is demonstrated in Pl. 2, fig. 19, where four distinct filaments have crossed in the centre (cf. Pénau, Hagemann, Velu \& Peyré, 1954: Pl. 1, fig. 7, for similar artefacts in growth of Streptomyces griseus).

When the development of such minute mycelia produced by different strains was examined at intervals in a large number of slide cultures, it was found to follow the classical lines already described. In pure cultures derived from known cells no cocci or cells that could possibly be described as spores (cf. Morris, 1951) appeared at any stage. The colonies developed in characteristic fashion with a somewhat rough or pebbled surface, due to the constant interlacing of filaments branching in varying directions (Pl. 2, figs. 13, 14). Sometimes a few aerial filaments could be seen. Their emergence appeared dependent upon a variety of physical and chemical factors such as composition and consistency of medium, degree of humidity in culture vessel, and local surface tensions. In young colonies they were quickly overgrown, and in old ones they withered away; in no instances did they exhibit any reproductive function.

The success of the water + gel system (Erikson \& Masson, 1954: fig. 2) for the cultivation of single cells of Actinomyces israelii led to the general use of a modified method based on that of Heald et al. (1953), which proved unexpectedly valuable both for the maintenance of stock and the detection of any impurities.

\section{Use of water + gel system for detection of commensals}

The use of shake cultures, particularly in rich glucose-containing media, has long been found satisfactory (see Wright, 1905) in the cultivation of anaerobic actinomycetes which, according to size and vigour of inoculum, tend to grow in a dense zone about half an inch below the surface when incubated aerobically. In the regular routine of weekly subculturing over a period of 2-3 years, it was constantly found that the colonies in such agar deeps (using $\mathbf{S}$ medium and $1-1.5 \%$ agar) retained their nodular circumscribed character. Only when a gross contamination was present was there any 'tailing' visible, reminiscent of various eubacterial growths in agar depths. In the case of the strain 1394 ' $s$ foft' cultures, the single colonies towards the bottom of the tube or bottle showed no such spreading downwards into the agar, and consistently exhibited an entire outline though it was somewhat smoother than usual. No surface growth was ever apparent. When, however, the shake cultures were made in bottles layered with water in the manner described in the section on Methods, two noteworthy facts were evident: (1) the quantity of growth in the gel was considerably greater than in duplicate sets sown from the same suspension into the same medium, but incubated without a water layer-whether aerobically or anaerobically; (2) in certain bottles of strain 1394 a smooth soft growth composed mainly of cocci (Pl. 1, fig. 11) appeared at the medium/water interface.

These observations were repeatedly confirmed. In the case of the pure line strains, the good yield obtained by this method was further enhanced if, after 
5-7 days, the supernatant water was removed and carefully replaced with fresh sterile water. Growth then continued for another 7-10 days, especially in a soft $(0.5 \%)$ agar, and seemed to follow from the removal of the acid products of metabolism which were found in the initial water phase. The provision of such a water layer, into which possibly toxic substances arising from the growth of the dominant organism were able to diffuse, also proved to be the readiest way of securing a favourable environment for the demonstration and characteristic growth of those few alien cells trapped within the actinomycete mycelium. Atypically smooth soft growth on nutrient agar slopes which yet showed clarity in anaerobic liquid cultures, and whose cells were so preponderantly diphtheroid in aspect (cf. Pl. 1, fig. 2) that it was difficult to detect (microscopically) shorter coccoid cell elements therein, often showed by this gel + water method a minute smooth colony of cocci at the gel + water interface. At the same time the water + gel controls remained sterile. The effect of adding alien cells to established pure line cultures was then examined.

\section{Admixture of alien cells to pure Actinomyces israelii strains}

Six morphologically different aerobic organisms, selected at random from common contaminants found in animal lesions (two staphylococci, one streptococcus, one diphtheroid, one sporing rod, one coliform organism) were added in minute quantities (the organisms which adhered to a needle-tip pressed lightly against a single colony) to each of six young replicate broth tubes of a pure culture of Actinomyces israelii. These cultures were then incubated anaerobically, continued in regular weekly subculture for 3-4 months, then later freeze-dried and opened 1 year later. The cultures with the coliform and diphtheroid admixtures grew very poorly and ultimately died out. A moderate growth of the actinomycete was obtained with the streptococcus and spore-former mixtures, but the fact that they were mixtures was evident after a few generations. The staphylococcal mixtures continued growth in the manner described for the soft culture of strain 1394: the alien cells found the conditions unfavourable for growth to any considerable extent as long as the cultures were maintained anaerobically and subcultured frequently, but were carried over in small numbers within the network of granules, ready to multiply whenever a more suitable substrate was supplied or when the cultures were left standing in an atmosphere of air. These cultures survived freeze-drying and produced a typical soft growth in agar shakes.

\section{'Associates' in animal lesions}

It is not possible to give data concerning primary associates of actinomycetes in the animal material examined, for closed lesions removed under aseptic conditions were not available. All the specimens received were considerably and sometimes very grossly contaminated, mainly with staphylococci but also with streptococci, diphtheroids, and a great variety of other organisms. This was particularly true of the bovine soft tissues such as cheek and retropharyngeal glands. Of about 120 specimens obtained from various veterinary 
sources only $c .15 \%$ showed on microscopical examination any branching filamentous or diphtheroid cells which could possibly be ascribed to actinomycete growth. 'Clubs' were found in not more than $5 \%$ of cases. Cultures which showed some characteristics of anaerobic actinomycetes were obtained in $10 \%$ of cases, as follows: 3 from bovine jaw; 2 from bovine lung; 4 from bovine soft head tissues; and 3 from sow udder.

Of the bovine specimens two, which were obtained locally, were outstanding cases of advanced actinomycosis. One specimen $(\mathrm{J} 2)$ was a jawbone with a large cavity which was filled with pus containing granules which crushed easily and showed a beautiful text-book picture of 'clubs'. Microscopically, Grampositive branching filaments with some coccoid bodies dominated the smears. The culture obtained was somewhat soft in the first few generations, but was undoubtedly Actinomyces israelii; when subcultured during 2 years it showed no marked morphological or biochemical differences from human strains. The other specimen ( $L$ 1) was an entire lung oozing pus in which there were abundant egg-shaped granules. These granules when washed free from pus cells were smaller than those in specimen $\mathbf{J} 2$, and the clubs were also smaller. The smears revealed filaments which were much shorter and less branched, with a greater proportion of coccoid elements. The organism that was isolated grew rather poorly in a soft short-filamented form, but with further purification it was also shown to be $A$. israelii. Neither of these organisms was as vigorous in artificial culture as were the human strains, and it is probable that each continued to harbour a few coccal cells which eventually swamped the cultures when they were unavoidably put aside for a time.

All the other bovine organisms were isolated from material which was far from fresh or had been sent through the post; these specimens carried such a mixed flora that it was impossible to feel any confidence concerning the etiological role of the isolates. In all instances they were the smooth soft type of organism, often growing with difficulty and yielding inconsistent results. Few of them survived any lengthy period of cultivation, and this was attributed to the impairment of vigour following on severe microbial competition in the tissues. Yet all showed more resemblance to Actinomyces israelii than to the pre-eminently diphtheroid $A$. bovis described earlier (Erikson, 1940).

During the latter part of this work some cultures isolated from bovine material by various veterinarians were received which showed very little, if any, branching of filaments and production of mycelium. When received on such complex media as blood agar, the very small soft smooth flat colonies sometimes showed an extremely pleomorphic picture of short rods, coccoid bodies, and occasional branching filaments of varying widths which resembled the schematic diagrams of Morris (1951). One such culture was dissected by means of the micro-manipulative methods of Erikson \& Masson (1954), and an aerobic Gram-positive coccus was obtained from it in single-cell culture. The anaerobic diphtheroid element, which was also isolated in single-cell culture, grew well in a semi-solid yeast + peptone + lactate medium, suggesting that this organism might be related more closely to the propionibacteria (see Gutierrez, 1953). 
All three specimens of sow udder contained orthodox granules surrounded by clubs, and relatively few contaminants. The organisms isolated were definitely strains of Actinomyces israelii. One of these strains was previously shown (Erikson \& Porteous, 1953) to be culturally and biochemically identical with the human strains.

\section{DISCUSSION}

After summarizing the relevant literature in a discussion on this subject written 15 years ago, Erikson (1940) stated that 'the israeli type is preponderantly human in incidence, although it may occur elsewhere, notably in swine and occasionally in cattle; while the soft-growing form is most often found in the jaws-though again also in other regions-of cattle'. On the basis of our present evidence we can confirm the pre-eminence of Actinomyces israelii in actinomycosis of man and of pigs, but we must also admit that it can be found in the jaws and other regions of cattle exhibiting the gross pathology of the disease. Thompson (1950) found one case of $A$. israelii and fourteen soft $A$. bovis types in lumpy jaw of cattle.

The discovery that a typical strain of Actinomyces israelii could harbour a number of alien cells without showing obvious signs of contamination so long as the cultures were maintained under anaerobic conditions and subcultured regularly illumines aspects (2) and (3) of the problem outlined at the beginning of this paper, namely that of the conversion of hard 'rough' to soft 'smooth' growth. All the phenomena described for strain 1394-tolerance of oxygen, more profuse growth of short cell elements, turbidity in liquid media and soft smooth colonies on solids-are those which have been described in the literature as characteristic of various atypical non-israelii forms of Actinomyces. The marked inconsistency of the bovine forms which we obtained and their tendency to die out when transferred to simpler media are features indicative of contamination. They also closely parallel the experience of Magnusson (1928), who, referring to 54 isolates from bovine lumpy jaw, stated: 'it is well nigh impossible to test this organism... for it grows quite differently on different occasions, although the same culture strains and the same medium are employed'.

The possibility that associated bacteria influence the mode of growth and the morphology of the actinomycetes was suggested long ago by Alissow \& Skworzow (1898). Our experiments involving deliberate contamination of pure cultures of Actinomyces israelii demonstrate the ability of vigorous young growths to incorporate certain random associates, at least for a period, without major disturbance in the economy of the dominant organism. The ease with which such intimate mixtures can be carried on to isolation plates can readily be granted if we bear in mind the low viability ratio of single cells of the actinomycete (Erikson, 1940, pp. 14-17; Erikson \& Masson, 1954), the probability that many colonies are derived from small filamentous complexes, and the experience of Holm (1950) based upon the examination of 650 human specimens, who graphically described the associates as being 'found grouped between and up against the definitely characteristic, often delicately coiled, 
Gram-positive actinomyces filaments'. It is also significant that some of Holm's isolates are of the soft smooth type, and that all have been cultivated on very complex media.

Other workers, e.g. Beerens (1953) have classed human and bovine actinomycetes together with various corynebacteria. Since the cultures of Beerens developed a pinkish tinge in their soft smooth colonies, it seems likely that they all were indeed corynebacteria. In our experience no genuine actinomycetes with anaerobic requirements have at any time displayed any pigmentation. On the other hand, there does seem to be another type of microaerophilic diphtheroid organism to be found in bovine lesions. This is the organism described as Actinomyces bovis by Erikson (1940), which was isolated from soft tissues in Australian cattle. This organism differed serologically and biochemically from $A$. israelii, and produced very small flat colonies dissimilar in many respects from the soft smooth types of growth encountered during the present investigation. Certain strains resembling this $A$. bovis form were received towards the close of this work, as mentioned earlier, from various veterinarians in this country-in particular from $\mathrm{Mr}$ M. B. Hawksley of the Royal Veterinary College, London. His strains were serologically distinct from $A$. israelii (personal communication) and our preliminary examination revealed biochemical differences. The question of the generic status of $\boldsymbol{A}$. bovis, however, is yet to be settled, namely whether the organism is indeed an Actinomyces sp. or is more properly to be considered a Propionibacterium sp., for branching was infrequent and dependent on cultural conditions.

Our experience leads us to believe that it is now time for a re-appraisal of the concept of smooth soft forms of anaerobic actinomycetes; a concept which may include different associations of Actinomyces israelii living commensally with other organisms or that of a quite distinct organism.

An expenses grant was received from the Medical Research Council during the early part of this. work. We wish to thank: the many veterinarians who sent in specimens in response to an appeal from Mr W. A. Pool, M.R.C.V.S., of the Commonwealth Bureau of Animal Health, Weybridge, Surrey; Mr W. MacDonald of the Aberdeen Flesher Incorporation for a large variety of morbid material; Mr P. Bruce of Robert Lawson and Sons Ltd., Dyce, Aberdeenshire, for specimens of infected sow udder; Miss F. M. Masson of the Rowett Research Institute for help with the micromanipulations; Miss Mildred Mackay for technical assistance. This work was done by the senior author (D. E.) as a member of the scientific staff of the Agricultural Research Council, and she wishes to thank Prof. J. Cruickshank, C.B.E., for the hospitality of his department; the junior author was in receipt of a personal grant from the Medical Research Council and wishes to thank Prof. W. O. Kermack for the hospitality of his department.

\section{REFERENCES}

Alrssow \& Skworzow (1898). Medizinskoje Obosrenje. Cited by Holm, P. (1950). Studies on the etiology of human actinomycosis. I. The 'other microbes' of human actinomycosis and their importance. Acta path. microbiol. scand. 27, 736.

Bates, R. (1933). Actinomycosis. Lancet, 1, 571. 
Beerens, H. (1953). Étude comparative de six souches des bactéries anaérobies non sporulées. Ann. Inst. Pasteur, 84, 1026.

Bisset, K. A. \& Moore, F. W. (1949). The relationship of certain branched bacterial genera. J. gen. Microbiol. 3, 387.

Colebrook, L. (1920). The mycelial and other micro-organisms associated with human actinomycosis. Brit. J. exp. Path. 1, 197.

ErIKson, D. (1940). Pathogenic anaerobic organisms of the Actinomyces group. Spec. Rep. Ser. med. Res. Coun., Lond. no. 240.

Erikson, D. \& MASson, F. M. (1954). Modifications of micromanipulative practice suitable for single cell isolation and cultivation of $(a)$ aerobic and transiently chain-forming, (b) lipophilic and (c) microaerophilic bacteria. J. gen. Microbiol. $11,209$.

Erikson, D. \& Porteous, J. W. (1953). The cultivation of Actinomyces israelii in a progressively less complex medium. J. gen. Microbiol. 8, 464.

De Fonbrune, P. (1949). Technique de Micromanipulation. Paris: Masson.

Gutierrez, J. (1953). Numbers and characteristics of lactate utilizing organisıns in the rumen of cattle. J. Bact. 66, 123.

Heald, P. J., Krogh, N., Mann, S. O., Appleby, J. C., Masson, F. M. \& Oxford, A. E. (1953). A method for direct viable counts of the facultatively anaerobic microflora in the rumen of a sheep maintained on a hay diet. J. gen. Microbiol. 9, 207.

Holm, P. (1948). Some investigations into the penicillin sensitivity of humanpathogenic actinomycetes. Acta path. microbiol. scand. 25, 376.

Holm, P. (1950). Studies on the etiology of human actinomycosis. I. The 'other microbes' of actinomycosis and their importance. Acta path. microbiol. scand. 27, 736 .

Kimball, A. \& Frank, E. R. (1945). 'The isolation of Actinomyces bovis from fistulous withers and poll evil. Amer. J. vet. Res. 6, 39.

Klinger, R. (1912). Untersuchungen über menschliche Aktinomykose. Zbl. Bakt. (1. Orig.), 62, 191.

Lentze, F. A. (1938). Zur Bakteriologie und Vakzinetherapie der Aktinomykose. Zbl. Bakt. (1. Orig.), $141,21$.

Ludwig, T. G. \& Sullivan, H. R. (1952). Studies of the flora of the mouth. VIII. An examination of selected human strains of anaerobic Actinomyces. Aust. J. exp. Biol. med. Sci. 30, 81.

Magnusson, H. (1928). The commonest forms of actinomycosis in domestic animals and their etiology. Acta path. microbiol. scand. 5, 170.

Morris, E. O. (1951). The life cycle of Actinomyces bovis. J. Hyg., Camb. 49, 46.

Pénau, H., Hagemann, G., Velu, H. \& Peyré, M. (1954). Modalités du cycle évolutif de 'Streptomyces griseus' en culture profonde. Rev. d'Immunol. 18, 265.

Prévot, A. R. (1953). Morphologie, physiologie, pouvoir pathogène et systématique des Actinomycetales anaërobies. In Actinomycetales, Symp. VIth Congr. int. Microbiol. p. 40.

Slack, J. M., Ludwig, E. H., Bird, H. H. \& CAnby, C. M. (1951). Studies with microaerophilic actinomycetes. 1. The agglutination reaction. J. Bact. 61, 721 .

Thompson, L. (1950). Isolation and comparison of Actinomyces from human and bovine infections. Proc. Mayo Clin. 25, 81.

Wright, J. H. (1905). The biology of the micro-organisms of actinomycosis. J. med. Res. 13, 349. 


\section{EXPLANATION OF PLATES}

(All phase contrast preparations.)

Plate 1

Fig. 1. Filamentous margin of microcolony of 'soft' growth of strain 1394 in liquid S medium, 10 days. $(\times 2160$. $)$

Fig. 2. Portion of growth in Pl. 1, fig. 1, compressed between slide and coverslip, showing component cells mainly rod-like with little branching. $(\times 2160$. $)$

Fig. 3. Short cell elements in D liquid culture of 1394,6 days. $(\times 2160$.)

Fig. 4. Occasional filamentous extension in same culture as in Pl. 1, fig. $3 .(\times 2160$. $)$

Fig. 5. Rarer characteristic branched growth from same culture as in Pl. 1, fig. 3. $(\times 2160$. $)$

Fig. 6. Cell complex in $F$ liquid medium, showing irregular elements and some degree of lysis, 10 days. $(\times 2160$. $)$

Fig. 7. Another replicate of same culture as in Pl. 1, fig. 6, showing vigorous growth of rods and short filaments, with a coccus simulating a bud. $(\times \mathbf{2 1 6 0}$. $)$

Fig. 8. Portion of growth from same tube as in Pl. 1, fig. 6, showing cocei adhering to short rods so that occasionally they appear stalked. $(\times 3360$.)

Fig. 9. Another field in same specimen as in P1. 1, fig. 8, showing clumping of cocci. $(\times 3360$. $)$

Fig. 10. Another replicate of same culture as in Pl. 1, fig. 6, showing partial lysis of microcolony. $(\times 2400$.

Fig. 11. Strain 1394 at medium/water interface in water/gel S bottle culture, showing almost pure culture of cocci in smooth soft growth, 7 days. $(\times 2160$.

Fig. 12. Strain 1394 from a smooth colony on $D$ agar medium incubated anaerobically, showing mainly diphtheroid and rod-shaped elements, 7 days. $(\times 2160$.)

\section{Plate 2}

Fig. 13. Pure single-celled strain (Wills) plated on $\mathbf{S}$ medium, showing small colony with rough pebbled aspect and occasional aerial filament, 12 days. $(\times 1500$.)

Fig. 14. Enlargement of colony in Pl. 2, fig. 13. ( $\times 3000$.

Fig. 15. Same strain grown in liquid $\mathbf{S}$ medium, showing short segmented filaments and occasional swollen club-shaped cells, 10 days. $(\times 1500$. $)$

Fig. 16. Progeny of culture in Pl. 2, fig. 15, in S slide culture, showing margin of microcolony with longer more homogeneous filaments developing between coverslip and medium, 5 days. $(\times$ 1500.)

Fig. 17. Enlargement of part of Pl. 2, fig. 16, showing twisting filaments at edge and dense bodies within one long basal filament. $(\times 3000$.)

Fig. 18. Another field of same specimen as in Pl. 2, fig. 16, showing the growing tip of the uppermost branch burrowing into the agar and so presenting a clavate appearance. $(\times 3000$.

Fig. 19. Another field in same specimen as in Pl. 2, fig. 16, focused upwards to show an artefact-the appearance of an enlarged cell where four distinct filaments have crossed $(\times 3000$.

Fig. 20. Another field of specimen in Pl. 2, fig. 16, showing characteristic angular apposition resulting from the slipping sideways of $V$-shaped branch. $(\times 3000$. $)$

Fig. 21. Another field of same specimen in PI. 2, fig. 16, showing overlaying of different branches, and at centre right the very beginning of a small branch in the form of a minute globular bud with very slender stalk. $(\times 3000$. $)$ 
Journal of General Microbiology, Vol. 13, No. 2
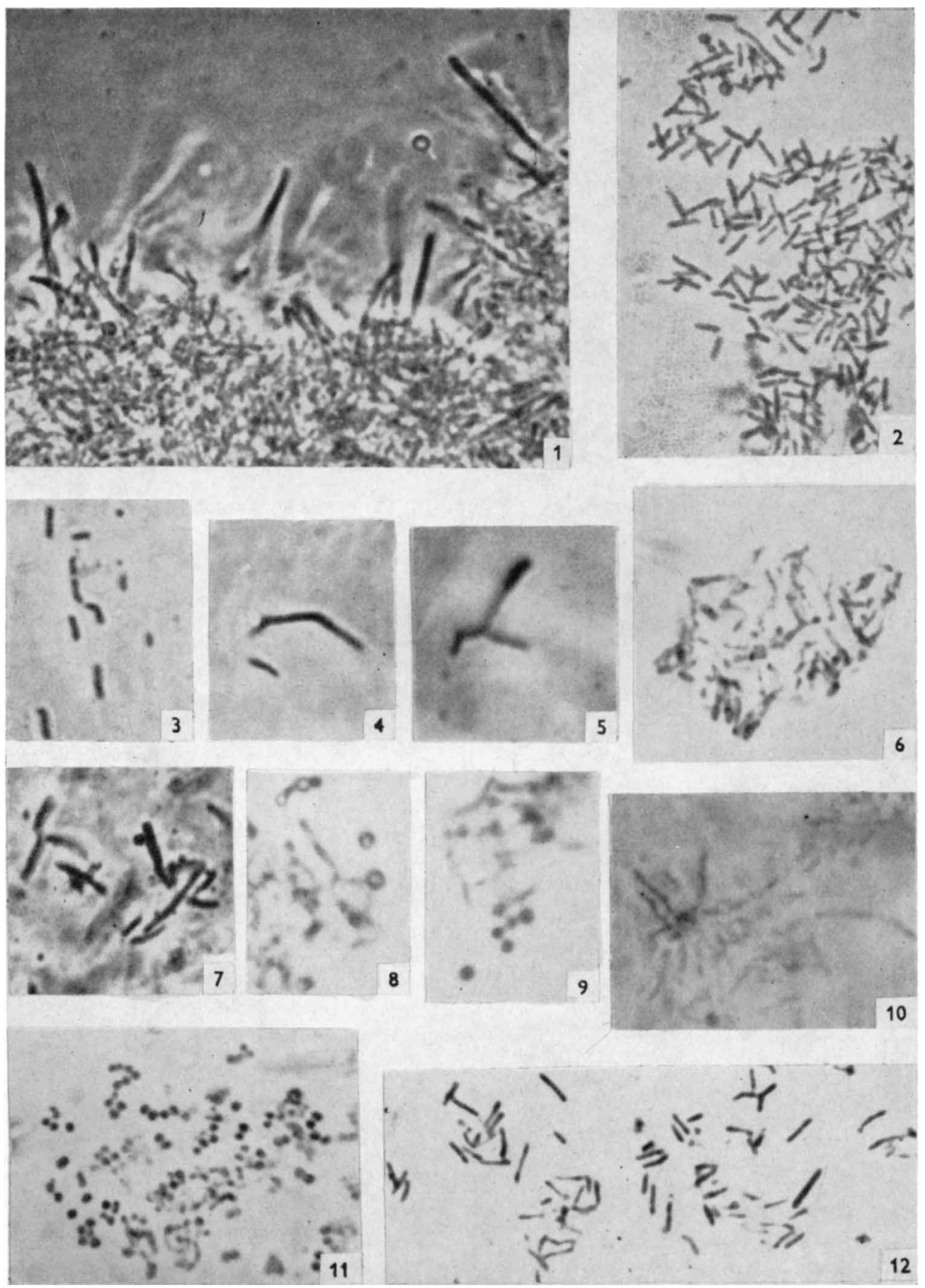

D. Erikson \& J. W. Porteous-Commensalism in anaerobic actinomycetes.

Plate 1 
Journal of General Microbiology, Vol. 13, No. 2
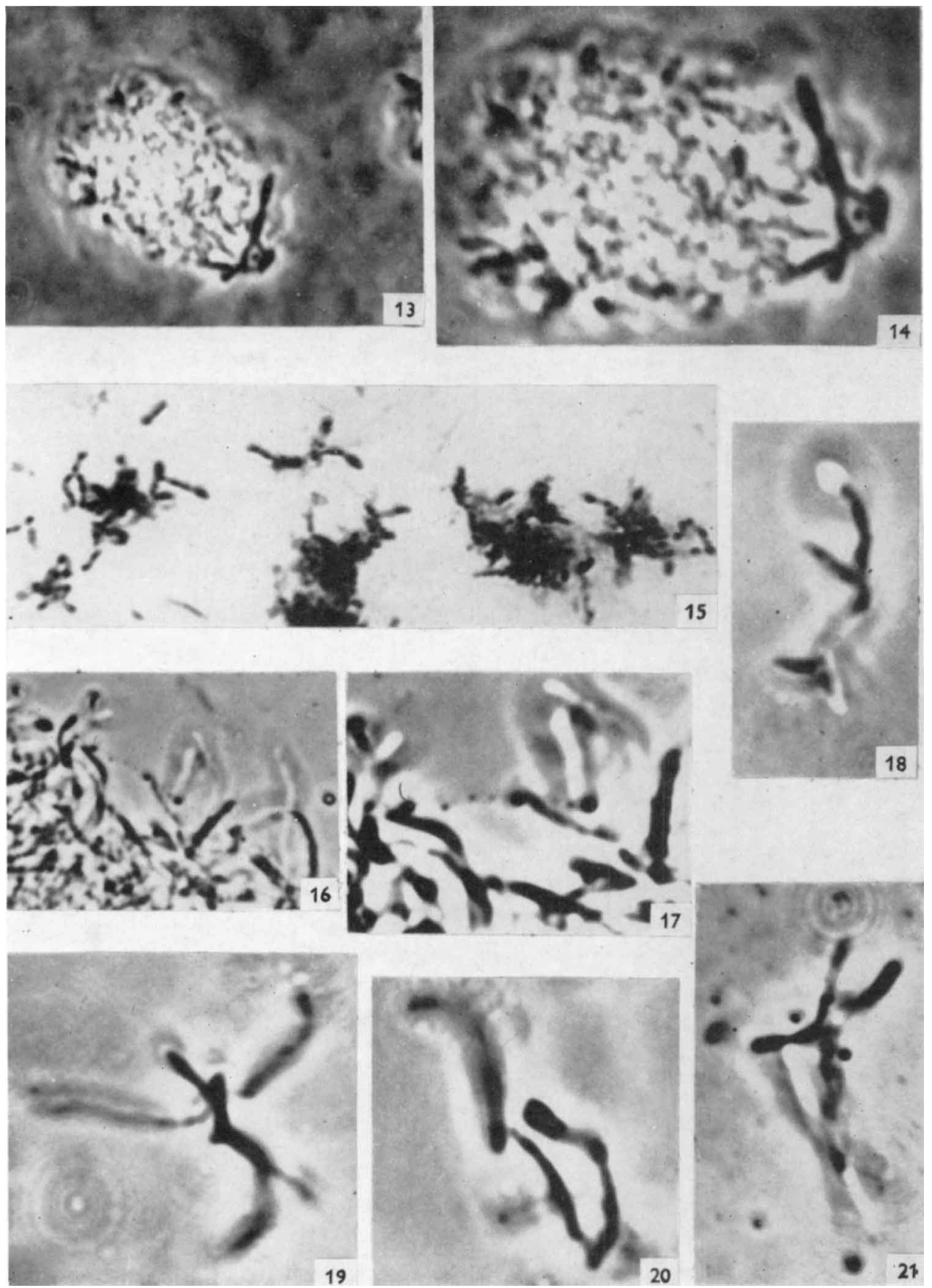

D. Erikson \& J. W. Porteous-Commensalism in anaerobic aC'inomychtes. Plate 2 